\title{
Pooled analysis of combination antiemetic therapy for chemotherapy-induced nausea and vomiting in patients with colorectal cancer treated with oxaliplatin-based chemotherapy of moderate emetic risk
}

\author{
Mototsugu Shimokawa ${ }^{1,2^{*}}$, Toshinobu Hayashi ${ }^{3}$, Junichi Nishimura ${ }^{4}$, Taroh Satoh ${ }^{5}$, Mutsumi Fukunaga ${ }^{6}$,
} Reiko Matsui ${ }^{7}$, Yasushi Tsuji ${ }^{8}$, Fumitaka Mizuki ${ }^{9}$ and Takahiro Kogawa ${ }^{10}$

\begin{abstract}
Background: Among patients with colorectal cancer (CRC) treated with oxaliplatin (L-OHP)-based chemotherapy, delayed chemotherapy-induced nausea and vomiting (CINV) have not been well controlled.

Methods: We pooled data from two prospective observational studies in Japan and one phase III clinical trial to assess whether delayed CINV could be controlled with a combination of three antiemetics adding a neurokinin-1 receptor antagonist and identified individual risk factors, using an inverse probability treatment-weighted analysis.

Results: A total of 661 patients were evaluable in this study (median age: 64 years; 391 male, and 270 female). 3 antiemetics controlled delayed nausea (33.18\% vs. $42.25 \% ; p=0.0510)$ and vomiting (4.15\% vs. $16.08 \% ; p<0.0001)$ better than with 2 antiemetics. Female and 2 antiemetics were risk factors for both delayed nausea (female —odds ratio [OR]: 1.918; 95\% confidence interval [CI]: 1.292-2.848; $p=0.0012 ; 2$ antiemetics—OR: 1.485; 95\% Cl: 1.000-2.204; $p=0.0498$ ) and delayed vomiting (female-OR: 2.735; 95\% Cl: 1.410-5.304; $p=0.0029 ; 2$ antiemetics-OR: 4.551; 95\% Cl: $2.116-9.785 ; p=0.0001)$.
\end{abstract}

Conclusions: Identifying individual risk factors can facilitate personalized treatments for delayed CINV. We recommend a 3-antiemetic combination prophylaxis for CRC patients treated with L-OHP-based chemotherapy, especially for female patients.

Keywords: Chemotherapy, Nausea, Vomiting, Colorectal cancer, Antiemetics, Oxaliplatin

\footnotetext{
* Correspondence: moto@yamaguchi-u.ac.jp

'Department of Biostatistics, Yamaguchi University Graduate School of Medicine, 1-1-1 Minamikogushi, Ube, Yamaguchi 755-8505, Japan

${ }^{2}$ Clinical Research Institute, National Hospital Organization Kyushu Cancer Center, Fukuoka, Japan

Full list of author information is available at the end of the article
}

(c) The Author(s). 2021 Open Access This article is licensed under a Creative Commons Attribution 4.0 International License, which permits use, sharing, adaptation, distribution and reproduction in any medium or format, as long as you give appropriate credit to the original author(s) and the source, provide a link to the Creative Commons licence, and indicate if changes were made. The images or other third party material in this article are included in the article's Creative Commons licence, unless indicated otherwise in a credit line to the material. If material is not included in the article's Creative Commons licence and your intended use is not permitted by statutory regulation or exceeds the permitted use, you will need to obtain permission directly from the copyright holder. To view a copy of this licence, visit http://creativecommons.org/licenses/by/4.0/ The Creative Commons Public Domain Dedication waiver (http://creativecommons.org/publicdomain/zero/1.0/) applies to the data made available in this article, unless otherwise stated in a credit line to the data. 


\section{Background}

Colorectal cancer (CRC) is the third most commonly diagnosed cancer in the world [1]. Oxaliplatin (L-OHP)based chemotherapy regimens, such as FOLFOX (5-fluorouracil + leucovorin + L-OHP) or XELOX (capecitabine + L-OHP) are preferred standard treatments for CRC [2-5]. Whereas chemotherapy-induced nausea and vomiting (CINV) were less prevalent for CRC patients on fluorouracil-based chemotherapy, they are a common adverse event for patients treated with L-OHP. In the MOSAIC trial, among patients on the FOLFOX and fluorouracil + leucovorin (FL) regimens, respectively, 73.7 and $61.1 \%$ had all-grade nausea (grades 3-4: 5.1 and $1.8 \%$ ); and 47.2 and $24.0 \%$ had all-grade vomiting (grades 3-4: 5.8 and 1.4\%) [6].

CINV impairs patients' quality of life and often causes delay or refusal of curative chemotherapy among such patients [7]. Antiemetic treatment has been greatly improved by the development of second-generation 5hydroxytryptamine-3 receptor antagonists (5HT3RAs; e.g., palonosetron) and neurokinin-1 receptor antagonists (NK1RAs). International guidelines for antiemetic therapy [8-10] include those published by the Japanese Society of Clinical Oncology in 2010 [11] and revised in 2015 [12]. However, control of delayed CINV is an unsolved issue $[13,14]$. Especially, patients who receive receiving either high (HEC) or moderate (MEC) emetogenic chemotherapy have a high incidence of CINV. Although these guidelines consistently recommend antiemetic prophylaxis with 5HT3RAs, steroids and NK1RAs for patients on HEC, [8-10] whether adding a NK1RA to a 5HT3RA and dexamethasone is beneficial for patients on MEC is controversial. Taking a combination of two antiemetics (2antiemetics)5HT3RAs and steroids-before receiving L-OHP resulted in a 90\% complete response (CR) for control of nausea and vomiting during the $24 \mathrm{~h}$ after chemotherapy. However, CR for delayed CINV (i.e., after $24 \mathrm{~h}$ and up to a week) decreased to $54 \%$ if an additional antiemetic agent was not prescribed. This finding implies a need for routine antiemetic prophylaxis for delayed CINV following L-OHP-based chemotherapy [13].

Risk factors associated with CINV were reported to include younger age, female sex, a history of CINV, and low alcohol consumption [15-23]. However, these results were based on analyses of patients with various cancers, including many patients with breast cancer. Identifying risk factors for CINV in patients with CRC is important to providing them with appropriate care. Combinations of 3 antiemetics-2 antiemetics and NK1RA-for L-OHP-based chemotherapy were tested with a few studies; their clinical benefit is still under debate [24]. Our previous study indicated that 3 antiemetics treatment for CRC patients treated with L-OHP alleviated delayed vomiting without decreasing delayed nausea, [25] and XELOX caused a higher rate of nausea than FOLFOX. We considered these findings to reflect the study's small sample size. We hypothesized that 3 antiemetics treatment is independent prophylaxis for delayed CINV, and XELOX is similar to FOLFOX regarding CINV.

We therefore investigated whether delayed CINV were controlled with 3 antiemetics treatment, as well as risk factors for delayed CINV in CRC patients treated with L-OHP-based chemotherapy, based on two prospective cohort studies $[25,26]$ and one randomized trial [27] in Japan.

\section{Methods}

\section{Patients and methods}

We analyzed pooled patient-level data from two multicenter, prospective observational studies. The individual study results were previously published or presented in a conference (study A, UMIN000005971 [25]; study B, no registry number available [26]; SENRI trial, UMIN000006456 [27]), and their designs are summarized in Table 1. Two prospective observational studies and one phase III clinical trial conducted among patients in Japan who were scheduled to receive MEC regimens; all were approved by institutional review boards or independent ethics committees at each site where they were performed. Written informed consent was obtained from all participating patients before any related study procedure was initiated.

\section{Data collection}

For all three studies, patients were required to be at least 20 years of age, have solid tumors, and be chemotherapy-naïve. Any nausea or vomiting that occurred between $24 \mathrm{~h}$ and 6-7 days from the day of receiving their anticancer agents was defined as delayed. Eligible patients took two antiemetics of palonosetron or older 5HT3 receptor antagonists (RAs): azasetron, ramosetron and granisetron, and dexamethasone, all of which were administered within one hour before the scheduled L-OHP-based chemotherapy regimens. Aprepitant was optional in addition to two antiemetics.

\section{Statistical analysis}

Patient demographics and delayed CINV incidences were summarized using descriptive statistics or contingency tables, and compared using Student's $t$-test or chisquare test. We used an inverse probability treatmentweighted (IPTW) model derived from a logistic regression model to balance out observable characteristics among the administered antiemetics. Independent risk factors for delayed CINV were also evaluated using logistic regression analysis with a backward elimination 
Table 1 Study/Trial summary

\begin{tabular}{llll}
\hline Study or trial & Number of cancer types & Patients, $\boldsymbol{n}$ & CRC patients on L-OHP-based chemotherapy \\
\hline Study A & 9 & 2068 & 160 \\
Study B & 4 & 400 & 157 \\
SENRI Trial & CRC only & 413 & 344 \\
\hline
\end{tabular}

method. Observed incidences of efficacy outcomes were compared between the 2 antiemetics and 3 antiemetics groups that included NK1RA, using Cochran-MantelHaenszel tests. $P<0.05$ was considered significant, and were two-sided. All statistical analyses were performed using SAS 9.4 (SAS Institute, Cary, NC, USA).

\section{Results}

Unweighted and weighted patient characteristics

We included 661 patients in this analysis (Study A: $n=$ 160 [24.2\%], Study B: $n=157$ [23.8\%], SENRI trial: $n=$ 344. [52.0\%]; 2 antiemetics: $n=441,3$ antiemetics: $n=$ 220). Baseline characteristics, including age, sex, motion sickness, drinking habit, L-OHP regimen and number of antiemetics, are shown in Table 2. Unweighted and weighted patient characteristics, stratified by 2 antiemetics versus 3 antiemetics, are listed in Table 3.

Percentages of patients aged $\geq 65$ years (unweighted) were 2 antiemetics: $46.0 \%$ and 3 antiemetics: $53.2 \%$ years. The 2 antiemetics group also included more patients with drinking habits $(p<0.0006)$ than the 3 antiemetics group.

Propensity scores between antiemetics groups were adequately balanced after IPTW adjustment, as patient characteristics of age $(p=0.8756)$, sex $(p=0.9518)$, motion sickness $(p=0.9905)$, drinking habits $(p=0.8909)$, and L-OHP regimens $(p=0.8541)$ were similar between the 2 antiemetics and 3 antiemetics groups.

\section{Control of CINV}

The IPTW-adjusted CINV incidence is shown in Fig. 1. Although the cohort as a whole had a high incidence of delayed nausea $(37.72 \%)$, the 3 antiemetics group had less delayed nausea (33.18\%) than the 2 antiemetics group $(42.25 \%)$, with borderline significance $(p=0.0510)$. Overall delayed vomiting incidence was low (10.13\%), but significantly lower in the 3 antiemetics group

Table 2 Patients' baseline characteristics

\begin{tabular}{|c|c|c|c|c|}
\hline Characteristics & Study $A(N=160)$ & Study B $(N=157)$ & SENRI trial $(N=344)$ & Overall $(N=661)$ \\
\hline & $n(\%)$ & $n(\%)$ & $n(\%)$ & $n(\%)$ \\
\hline \multicolumn{5}{|l|}{ Age } \\
\hline$<65$ years & 89 (55.6) & $92(58.6)$ & $160(46.5)$ & $341(51.6)$ \\
\hline$\geq 65$ years & $71(44.4)$ & 65 (41.4) & $184(53.5)$ & $320(48.4)$ \\
\hline \multicolumn{5}{|l|}{ Sex } \\
\hline Male & $92(57.5)$ & $88(56.1)$ & $211(61.3)$ & 391 (59.2) \\
\hline Female & $68(42.5)$ & 69 (43.9) & $133(38.7)$ & $270(40.8)$ \\
\hline \multicolumn{5}{|l|}{ Motion sickness } \\
\hline No & $143(89.4)$ & $135(86.0)$ & $282(82.0)$ & $560(84.7)$ \\
\hline Yes & $17(10.6)$ & $22(14.0)$ & $56(16.3)$ & $95(14.4)$ \\
\hline Unknown & $0(0.0)$ & $0(0.0)$ & $6(1.7)$ & $6(0.9)$ \\
\hline \multicolumn{5}{|l|}{ Drinking habit } \\
\hline No & $126(78.8)$ & 78 (49.7) & $245(71.2)$ & 449 (67.9) \\
\hline Yes & $34(21.3)$ & $79(50.3)$ & $93(27.0)$ & $206(31.2)$ \\
\hline Unknown & $0(0.0)$ & $0(0.0)$ & $6(1.7)$ & $6(0.9)$ \\
\hline \multicolumn{5}{|l|}{ Regimen } \\
\hline FOLFOX & 97 (60.6) & 79 (50.3) & $83(24.1)$ & $259(39.2)$ \\
\hline XELOX & $63(39.4)$ & $78(49.7)$ & $261(75.9)$ & $402(60.8)$ \\
\hline \multicolumn{5}{|l|}{ Antiemetics } \\
\hline 2 & $114(71.3)$ & $157(100.0)$ & $170(49.4)$ & $441(66.7)$ \\
\hline 3 & 46 (28.8) & $0(0.0)$ & $174(50.6)$ & $220(33.3)$ \\
\hline
\end{tabular}


Table 3 Unweighted and weighted baseline characteristics of patients with oxaliplatin-treated colorectal cancer, by number of antiemetic regimens

\begin{tabular}{|c|c|c|c|c|c|c|}
\hline \multirow[t]{2}{*}{ Characteristics } & \multicolumn{3}{|c|}{ Unweighted, $n$ (\%) } & \multicolumn{3}{|l|}{ Weighted, \% } \\
\hline & 2 antiemetics & 3 antiemetics & $p$-value & 2 antiemetics & 3 antiemetics & $p$-value \\
\hline Total & $153(100)$ & $29(100)$ & & & & \\
\hline \multicolumn{7}{|l|}{ Age } \\
\hline$<65$ years & $238(54.0)$ & $103(46.8)$ & 0.0830 & 46.26 & 47.00 & 0.8756 \\
\hline$\geq 65$ years & $203(46.0)$ & $117(53.2)$ & & 53.74 & 53.00 & \\
\hline \multicolumn{7}{|l|}{ Sex } \\
\hline Male & $265(60.1)$ & $126(57.3)$ & 0.4873 & 56.86 & 57.14 & 0.9518 \\
\hline Female & $176(39.9)$ & $94(42.7)$ & & 43.14 & 42.86 & \\
\hline \multicolumn{7}{|l|}{ Motion sickness } \\
\hline No & $378(86.7)$ & $182(83.1)$ & 0.2181 & 82.91 & 82.95 & 0.9905 \\
\hline Yes & $58(13.3)$ & 37 (16.9) & & 17.09 & 17.05 & \\
\hline Unknown & $5(1.1)$ & $1(0.5)$ & & & & \\
\hline \multicolumn{7}{|l|}{ Drinking habit } \\
\hline No & $281(64.2)$ & $168(77.4)$ & 0.0006 & 77.97 & 77.42 & 0.8909 \\
\hline Yes & $157(35.8)$ & 49 (22.6) & & 22.03 & 22.58 & \\
\hline Unknown & $3(0.7)$ & $3(1.4)$ & & & & \\
\hline \multicolumn{7}{|l|}{ Regimen } \\
\hline FOLFOX & $180(40.8)$ & 79 (35.9) & 0.2233 & 35.56 & 36.41 & 0.8541 \\
\hline XELOX & $261(59.2)$ & $141(64.1)$ & & 64.44 & 63.59 & \\
\hline
\end{tabular}

(4.15\%) than in the 2 antiemetics group $(16.08 \% ; p<$ $0.0001)$.

\section{Risk factors for CINV}

We performed univariate and multivariate logistic regression analyses of risk factors for delayed CINV,

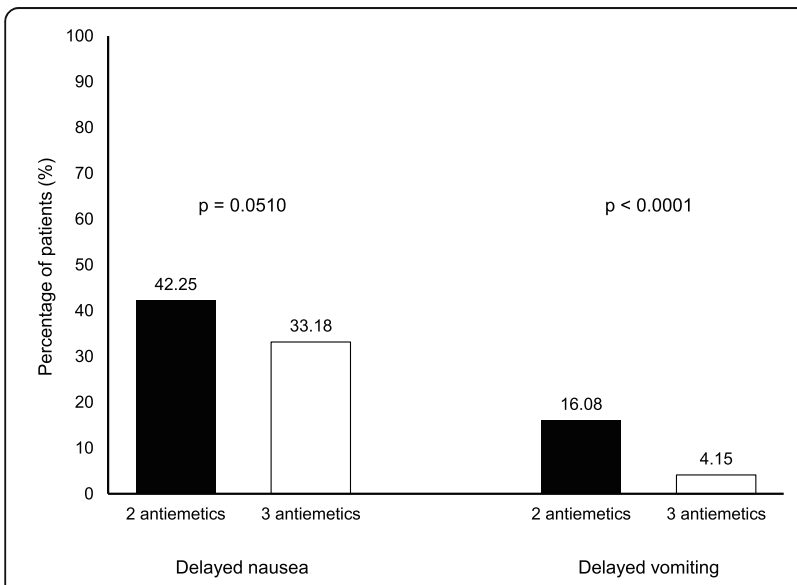

Fig. 1 Incidence of delayed CINV. Incidences of delayed CINV were adjusted using IPTW method. Black bars show the 2 antiemetics group, while white bars indicate the 3 antiemetics group. The incidence of delayed vomiting was significantly lower in the 3 antiemetics group than that in the 2 antiemetics group $(p<0.0001)$ including age, sex, motion sickness, drinking habit, LOHP-based regimen and antiemetic regimen (Table 4).

Known risk factors, [17-25] i.e., female sex, history of motion sickness and morning sickness, were identified as risk factors for delayed CINV, whereas patients who drank alcohol five times a week and who were older experienced CINV less frequently.

Female sex and use of only 2 antiemetics were associated with greater risks for both delayed nausea (female sex-OR: 1.918; 95\% CI: 1.292-2.848, $p=0.0012$; 2 antiemetics-OR: 1.485; 95\% CI: $1.000-2.204, p=0.0498$ ) and delayed vomiting (female sex-OR: 2.735; 95\% CI: 1.410-5.304, $p=0.0029 ; 2$ antiemetics: OR: 4.551; 95\% CI: $2.116-9.785, p=0.0001)$.

Logistic regression analysis showed female sex and 2 antiemetics regimens to be common risk factors for delayed CINV. Women were more susceptible to CINV than men in every aspect investigated (Fig. 2).

\section{Discussion}

The present study provides incidences of, and risk factors for, delayed CINV in CRC patients receiving LOHP-based chemotherapy, based on three prospective studies [25-27]. Delayed nausea occurred frequently but was less common in patients who received three antiemetics adding an NK1RA than those who received two antiemetics. Delayed vomiting incidence was relatively 
Table 4 Risk factors for delayed CINV

\begin{tabular}{|c|c|c|c|c|c|c|c|c|}
\hline & \multicolumn{4}{|l|}{ Delayed nausea } & \multicolumn{4}{|l|}{ Delayed vomiting } \\
\hline & Univariate & & Multivariate & & Univariate & & Multivariate & \\
\hline & OR $(95 \% \mathrm{Cl})$ & $p$-value & OR $(95 \% \mathrm{Cl})$ & $p$-value & OR $(95 \% \mathrm{Cl})$ & $p$-value & OR $(95 \% \mathrm{Cl})$ & $p$-value \\
\hline Age: $<65$ vs. $\geq 65$ years & $1.678(0.903-3.116)$ & 0.1014 & & & $1.976(0.614-6.354)$ & 0.2533 & & \\
\hline Sex: female vs. male & $1.909(1.288-2.829)$ & 0.0013 & $1.918(1.292-2.848)$ & 0.0012 & $2.636(1.378-5.044)$ & 0.0034 & $2.735(1.410-5.304)$ & 0.0029 \\
\hline Motion sickness: yes vs. no & $1.921(1.161-3.180)$ & 0.0111 & & & $2.027(0.993-4.138)$ & 0.0524 & & \\
\hline Drinking habit: yes vs. no & $1.361(0.843-2.196)$ & 0.2069 & & & $1.712(0.724-4.051)$ & 0.2208 & & \\
\hline Regimen: FOLFOX vs. XELOX & $1.067(0.713-1.597)$ & 0.7529 & & & $1.616(0.863-3.028)$ & 0.1339 & & \\
\hline 2 antiemetics vs. 3 antiemetics & $1.474(0.998-2.176)$ & 0.0514 & $1.485(1.000-2.204)$ & 0.0498 & $4.429(2.074-9.460)$ & 0.0001 & $4.551(2.116-9.785)$ & 0.0001 \\
\hline
\end{tabular}

low, and significant lower in the 3 antiemetics group. Multivariate analysis identified female sex and 2 antiemetics regimens as independent risk factors for delayed CINV.

Although adding a NK1RA to a 5HT3RAs and a steroid is well established and clearly recommended by all international guidelines for patients undergoing HEC, $[8-10,12]$ its benefit is still controversial for MEC other than carboplatin (CBDCA) -based regimens, and recommendations for using NK1RAs with MEC vary considerably among guidelines. As few clinical trials have attempted to clarify optimal antiemetic prophylaxis for CRC patients who receive L-OHP-based chemotherapy, evidence-based guidance in this setting is lacking.

Risk/benefit profiles and medication costs are important factors in treatment decisions, including antiemetic treatment. Choosing Wisely, an initiative of the American Board of Internal Medicine (ABIM) Foundation that seeks to advance a national dialogue on avoiding unnecessary medical tests, treatments and procedures, suggests that patients receiving MEC not use NK1RAs, for tolerability and economic reasons [28].

Iihara et al. [29] reported that use of two antiemetics-5HT3RA and dexamethasone-was sufficient for prevention of CINV in most MEC regimens, and found no significant differences in control of CINV among L-OHP, carboplatin and irinotecan. A recent meta-analysis [24] indicates that adding NK1RAs for patients undergoing L-OHP-based chemotherapy did not have a very pronounced effect. However, the two major studies that included patients with CRC with similar L$\mathrm{OHP}$ doses showed conflicting results. In addition, one of them used casopitant, which was never approved due to safety concerns. Therefore, the results have to be interpreted with caution. Hesketh et al. [13] advocated the need for routine antiemetic prophylaxis for delayed CINV following L-OHP-based chemotherapy. Tsuji et al. [25] reported that delayed nausea incidence was still high for MEC, and patients on L-OHP-based regimens seemed to benefit from doublet therapy with palonosetron or triplet therapy with aprepitant. Nishimura et al. [27] reported that three antiemetics that included aprepitant was more effective than two antiemetics in preventing $\mathrm{CINV}$ in $\mathrm{CRC}$ patients on L-OHP-based regimens. In addition, the antiemetic effects of aprepitant did not significantly differ whether combined with palonosetron or not. In the present study, although the 2 antiemetics group included patients who received palonosetron, it was less effective than the 3 antiemetics regimens.

Within the MEC classification, L-OHP has relatively high risks of CINV, as well as CBDCA, which suggests a different antiemetic prophylaxis strategy is appropriate. In the last update of the MASCC/ESMO guidelines, [9]
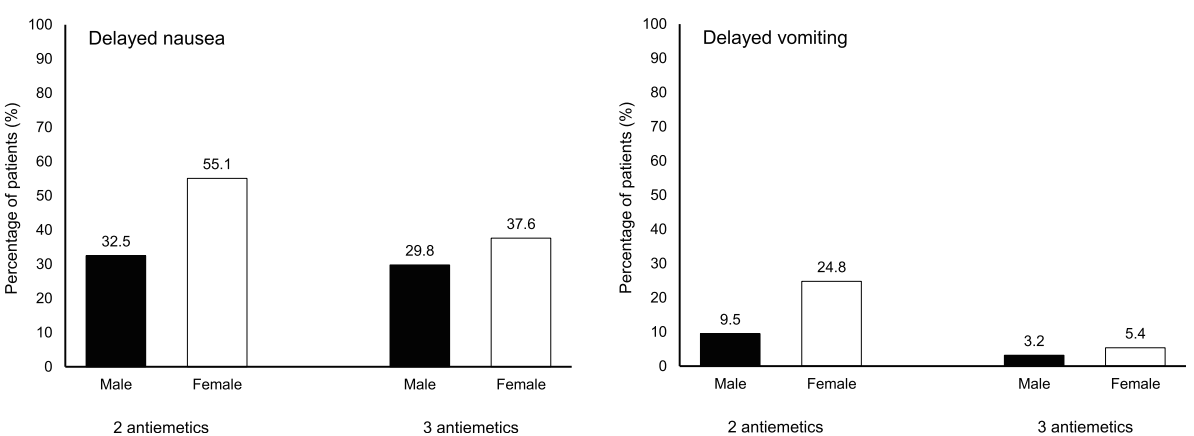

Fig. 2 Incidence of delayed CINV by risk factor. The graph displays analyses of incidences of delayed CINV of male (black bars) and female (white bars) between the 2 antiemetics group and the 3 antiemetics group 
experts discussed different recommendations for CBDCA-based and L-OHP-based chemotherapies, as L$\mathrm{OHP}$-based chemotherapy is estimated to carry a high emetic risk within MEC. The MASCC/ESMO guideline indicates that a $10 \%$ difference in CINV rates would be noticeable to the patient, [30] and appears to be a reasonable threshold to warrant a change in clinical practice. In the present study, 3 antiemetics regimens reduced delayed vomiting incidence by $11.93 \%$ and delayed nausea incidence by $9.07 \%$, compared with 2 antiemetics.

Younger age, female sex, a history of CINV, and low alcohol consumption have been reported as well-known risk factors [15-23]. Roscoe et al. [17] reported that a chemotherapy history was a stronger predictor than other predictors, including morning sickness, age, and motion sickness. Study cohorts for these reports included large percentages of breast cancer patients, whereas few studies of risk factors for CINV in CRC patients have been performed. Takemoto et al. [31] reported that female sex and aprepitant use were risk factors for CINV in CRC patients who received L-OHPbased chemotherapy, and that 3 antiemetics regimens that included aprepitant were more effective for women than for men in preventing CINV in this setting. Our integrated analysis showed that female sex and 2 antiemetics regimens were independent risk factors for both delayed nausea and delayed vomiting in CRC patients on L-OHP-based chemotherapy.

In the analysis focused on the efficacy of 3 antiemetics compared with 2 antiemetics containing palonosetron, a second-generation 5-HT3RA which is more effective than first-generation 5-HT3RAs against delayed CINV, 3 antiemetics was superior than 2 antiemetics for preventing delayed CINV, and female sex was identified as an independent risk factor for delayed vomiting [32].

In addition, the randomized trial in Chinese female patients with gastrointestinal cancer at high risk for CINV (younger than 50 years, no or low alcohol consumption) demonstrated significantly better antiemetic effect of 3 antiemetics, palonosetron plus dexamethasone plus aprepitant, compared with palonosetron plus dexamethasone for CINV caused by L-OHP or irinotecanbased chemotherapy [33].

On the other hand, the incremental benefits by adding aprepitant in men (3\% delayed nausea, 6\% delayed vomiting) was very small compared to women where the absolute benefits in delayed CINV are large in this study. These data suggest that 2 antiemetics for prevention of delayed CINV may be sufficient for men receiving LOHP-based regimen. Although there may be some operational issues such as the complexity electronic order sets at medical institutions, it is worth considering individualizing antiemetic prophylaxis by gender.
Our study also found no significant difference between XELOX and FOLFOX regimens with respect to delayed CINV, as we hypothesized. Many physicians prefer XELOX as it does not need continuous 5-FU infusion, and our results support XELOX administration.

\section{Study limitation}

The present study had some limitations. First, as its design was neither randomized nor blind, present findings should be interpreted within the limitations of the observational study design. Second, the two integrated studies had a bias in the number of patients, which we attempted to mitigate by using the IPTW method to balance the observable characteristics of the two antiemetic treatments. Despite these limitations, the findings describe CINV incidence and its risk factors in routine clinical practice, rather than in a controlled trial.

\section{Conclusions}

This study clarified that female sex and use of only two antiemetics are risk factors of delayed CINV for CRC patients who undergo L-OHP-based chemotherapy. We recommend combining three antiemetics as prophylaxis for CRC patients treated with L-OHP-based chemotherapy, especially female patients.

\section{Abbreviations \\ CRC: Colorectal cancer; L-OHP: Oxaliplatin; CINV: Chemotherapy-induced nausea and vomiting; IPTW: Inverse probability treatment-weighted; \\ OR: Odds ratio; Cl: Confidence interval; FOLFOX: 5-fluorouracil + leucovorin + oxaliplatin; XELOX: Capecitabine + oxaliplatin; FL: Fluorouracil + leucovorin; 5HT3RAs: 5-hydroxytryptamine-3 receptor antagonists; NK1RAs: Neurokinin-1 receptor antagonists; HEC: High emetogenic chemotherapy; MEC: Moderate emetogenic chemotherapy; CR: Complete response; RAs: Receptor antagonists; ABIM: The American Board of Internal Medicine; \\ CBDCA: Carboplatin; MASCC/ESMO: Multinational Association for Supportive Care in Cancer/ European Society for Medical Oncology}

\section{Acknowledgements}

We are grateful to Kazuo Tamura, Keisuke Aiba and Toshiaki Saeki for their helpful advice.

\section{Authors' contributions}

Mototsugu Shimokawa and Toshinobu Hayashi drafted the manuscript. Mototsugu Shimokawa, Toshinobu Hayashi, Junichi Nishimura, Taroh Satoh, Mutsumi Fukunaga, Reiko Matsui, Yasushi Tsuji, Fumitaka Mizuki, Takahiro Kogawa designed the study. Mototsugu Shimokawa was responsible for planning data analysis and analyzing the data resulting from this study. All named authors adhere to the authorship guidelines of Trials. All authors reviewed the manuscript and agreed to publication.

\section{Funding}

This study did not receive any specific grant from funding agencies in the public, commercial, or not-for-profit sectors.

\section{Availability of data and materials}

The data that support the findings of this study are available from two prospective observational studies and one phase III clinical trial but restrictions apply to the availability of these data, which were used under license for the current study, and therefore, the data are not publicly available. However, data are available from the authors upon reasonable request and with permission of all study groups. 


\section{Declarations}

\section{Ethics approval and consent to participate}

This study was approved by Independent Ethics Committee of National Hospital Organization Kyushu Cancer Center and conducted according to Declaration of Helsinki and the Ethical Guidelines for Medical and Health Research involving Human Subjects. Informed consent was waived from individual patients according to the Independent Ethics Committee of National Hospital Organization Kyushu Cancer Center.

\section{Consent for publication}

Not applicable.

\section{Competing interests}

Dr. Satoh has received grants and honoraria from Bristol-Myers, Chugai Pharmaceutical, Elli-Lilly, Merck, Merck serono, ONO Pharmaceutical, SanofiAventis, Taiho Pharmaceutical and Yakult Honsha, and received grants from Daiichi-Sankyo, Dainihon Sumitomo pharmaceutical and Gilead. He has received honoraria from Bayer, and received personal fees from Takara-Bio. Dr. Tsuji has received honoraria from Merck Serono, Eli Lilly Japan, Chugai, Taiho, Ono, Daiichi Sankyo, Yakult Honsha, Eisai and Medicon. Dr. Kogawa has received grants from Eli Lilly Japan, and Daiichi-Sankyo. Dr. Shimokawa, Dr. Hayashi, Dr. Nishimura, Dr. Fukunaga, Dr. Matsui and Dr. Mizuki have no conflicts of interest to declare.

\section{Author details}

'Department of Biostatistics, Yamaguchi University Graduate School of Medicine, 1-1-1 Minamikogushi, Ube, Yamaguchi 755-8505, Japan. ${ }^{2}$ Clinical Research Institute, National Hospital Organization Kyushu Cancer Center, Fukuoka, Japan. ${ }^{3}$ Department of Pharmaceutical and Health Care Management, Faculty of Pharmaceutical Sciences, Fukuoka University, Fukuoka, Japan. ${ }^{4}$ Department of Gastroenterological Surgery, Osaka International Cancer Institute, Osaka, Japan. ${ }^{5}$ Department of Frontier Science for Cancer and Chemotherapy, Graduate School of Medicine, Osaka University, Osaka, Japan. ${ }^{6}$ Department of surgery, Hyogo Prefectural Nishinomiya Hospital, Nishinomiya, Hyogo, Japan. 'Department of Pharmacy, National Cancer Center Hospital EastChiba, Kashiwa, Japan. ${ }^{8}$ Department of Medical Oncology, Tonan Hospital, Sapporo, Hokkaido, Japan. ${ }^{9}$ Center For Clinical Research, Yamaguchi University Hospital, Yamaguchi, Japan. ${ }^{10}$ Division of Early Clinical Development for Cancer, Advanced Medical Development Center, Cancer Institute Hospital of Japanese Foundation for Cancer Research, Tokyo, Japan.

Received: 11 June 2021 Accepted: 8 October 2021

Published online: 16 October 2021

\section{References}

1. World Health Organization. Cancer Fact sheet. 2021. https://www.who.int/ news-room/fact-sheets/detail/cancer. Accessed 2 Jun 2021.

2. Cassidy J, Clarke S, Díaz-Rubio E, Scheithauer W, Figer A, Wong R, et al. Randomized phase III study of capecitabine plus oxaliplatin compared with fluorouracil/folinic acid plus oxaliplatin as first-line therapy for metastatic colorectal cancer. J Clin Oncol Off J Am Soc Clin Oncol. 2008;26(12):200612. https://doi.org/10.1200/JCO.2007.14.9898.

3. Goldberg RM, Sargent DJ, Morton RF, Fuchs CS, Ramanathan RK, Williamson SK, et al. A randomized controlled trial of fluorouracil plus leucovorin, irinotecan, and oxaliplatin combinations in patients with previously untreated metastatic colorectal cancer. J Clin Oncol Off J Am Soc Clin Oncol. 2004;22(1):23-30. https://doi.org/10.1200/JCO.2004.09.046.

4. Schmoll H-J, Cartwright T, Tabernero J, Nowacki MP, Figer A, Maroun J, et al. Phase III trial of capecitabine plus oxaliplatin as adjuvant therapy for stage III colon cancer: a planned safety analysis in 1,864 patients. J Clin Oncol Off J Am Soc Clin Oncol. 2007;25(1):102-9. https://doi.org/10.1200/JCO.2006.08.1 075.

5. de Gramont A, Figer A, Seymour M, Homerin M, Hmissi A, Cassidy J, et al. Leucovorin and fluorouracil with or without oxaliplatin as first-line treatment in advanced colorectal cancer. J Clin Oncol Off J Am Soc Clin Oncol. 2000;18(16):2938-47. https://doi.org/10.1200/JCO.2000.18.16.2938.

6. André T, Boni C, Mounedji-Boudiaf L, Navarro M, Tabernero J, Hickish T, et al. Oxaliplatin, fluorouracil, and leucovorin as adjuvant treatment for colon cancer. N Engl J Med. 2004;350(23):2343-51. https://doi.org/10.1056/ NEJMoa032709.

7. Herrstedt J. Nausea and emesis: still an unsolved problem in cancer patients? Support Care Cancer Off J Multinatl Assoc Support Care Cancer. 2002;10:85-7.

8. Basch E, Prestrud AA, Hesketh PJ, Kris MG, Feyer PC, Somerfield MR, et al. Antiemetics: American Society of Clinical Oncology clinical practice guideline update. J Clin Oncol Off J Am Soc Clin Oncol. 2011;29(31):418998. https://doi.org/10.1200/JCO.2010.34.4614.

9. Roila F, Warr D, Hesketh PJ, Gralla R, Herrstedt J, Jordan K, et al. 2016 updated MASCC/ESMO consensus recommendations: prevention of nausea and vomiting following moderately emetogenic chemotherapy. Support Care Cancer Off J Multinatl Assoc Support Care Cancer. 2017;25:289-94.

10. National Comprehensive Cancer Network. NCCN clinical practice guidelines in oncology. Antiemesis Version 3. 2018. https://www.nccn.org/professiona Is/physician_gls/pdf/antiemesis.pdf.

11. Japan Society of Clinical Oncology. Guidelines for appropriate use of antiemetic drugs. Version 1. Tokyo: Kanehara; 2010.

12. Japan Society of Clinical Oncology. JSCO guidelines for antiemetics in oncology. Tokyo: Kanehara; 2015.

13. Hesketh PJ, Sanz-Altamira P, Bushey J, Hesketh AM. Prospective evaluation of the incidence of delayed nausea and vomiting in patients with colorectal cancer receiving oxaliplatin-based chemotherapy. Support Care Cancer Off J Multinatl Assoc Support Care Cancer. 2012;20(5):1043-7. https://doi.org/10.1 007/s00520-011-1180-2.

14. Hayashi T, Shimokawa M, Miyoshi T, Toriyama Y, Yokota C, Taniguchi J, et al. A prospective, observational, multicenter study on risk factors and prophylaxis for low emetic risk chemotherapy-induced nausea and vomiting. Support Care Cancer Off J Multinatl Assoc Support Care Cancer. 2017;25(9):2707-14. https://doi.org/10.1007/s00520-017-3679-7.

15. Roila F, Boschetti E, Tonato M, Basurto C, Bracarda S, Picciafuoco M, et al. Predictive factors of delayed emesis in cisplatin-treated patients and antiemetic activity and tolerability of metoclopramide or dexamethasone. A randomized single-blind study. Am J Clin Oncol. 1991;14(3):238-42. https:// doi.org/10.1097/00000421-199106000-00010.

16. Pollera CF, Giannarelli D. Prognostic factors influencing cisplatin-induced emesis. Definition and validation of a predictive logistic model. Cancer. 1989;64(5):1117-22. https://doi.org/10.1002/1097-0142(19890901)64:5<111 7::AID-CNCR2820640525>3.0.CO;2-R.

17. Roscoe JA, Bushunow P, Morrow GR, Hickok JT, Kuebler PJ, Jacobs A, et al. Patient expectation is a strong predictor of severe nausea after chemotherapy: a University of Rochester Community Clinical Oncology Program study of patients with breast carcinoma. Cancer. 2004;101(11): 2701-8. https://doi.org/10.1002/cncr.20718.

18. Sekine I, Segawa Y, Kubota K, Saeki T. Risk factors of chemotherapy-induced nausea and vomiting: index for personalized antiemetic prophylaxis. Cancer Sci. 2013;104(6):711-7. https://doi.org/10.1111/cas.12146.

19. du Bois A, Meerpohl HG, Vach W, Kommoss FG, Fenzl E, Pfleiderer A. Course, patterns, and risk-factors for chemotherapy-induced emesis in cisplatinpretreated patients: a study with ondansetron. Eur J Cancer Oxf Engl 1990. 1992:28:450-7.

20. Osoba D, Zee B, Pater J, Warr D, Latreille J, Kaizer L. Determinants of postchemotherapy nausea and vomiting in patients with cancer. Quality of life and symptom control committees of the National Cancer Institute of Canada clinical trials group. J Clin Oncol Off J Am Soc Clin Oncol. 1997; 15(1):116-23. https://doi.org/10.1200/JCO.1997.15.1.116.

21. Molassiotis A, Aapro M, Dicato M, Gascon P, Novoa SA, Isambert N, et al. Evaluation of risk factors predicting chemotherapy-related nausea and vomiting: results from a European prospective observational study. J Pain Symptom Manage. 2014;47:839-848.e4.

22. Tamura K, Aiba K, Saeki T, Nakanishi Y, Kamura T, Baba H, et al. Testing the effectiveness of antiemetic guidelines: results of a prospective registry by the CINV study Group of Japan. Int J Clin Oncol. 2015;20(5):855-65. https:// doi.org/10.1007/s10147-015-0786-7.

23. Pater J, Slamet L, Zee B, Osoba D, Warr D, Rusthoven J. Inconsistency of prognostic factors for post-chemotherapy nausea and vomiting. Support Care Cancer Off J Multinatl Assoc Support Care Cancer. 1994;2(3):161-6. https://doi.org/10.1007/BF00417474.

24. Jordan K, Blättermann L, Hinke A, Müller-Tidow C, Jahn F. Is the addition of a neurokinin-1 receptor antagonist beneficial in moderately emetogenic chemotherapy?-a systematic review and meta-analysis. Support Care Cancer 
Off J Multinatl Assoc Support Care Cancer. 2018;26(1):21-32. https://doi. org/10.1007/s00520-017-3857-7.

25. Tsuji Y, Baba H, Takeda K, Kobayashi M, Oki E, Gotoh M, et al. Chemotherapy-induced nausea and vomiting (CINV) in 190 colorectal cancer patients: a prospective registration study by the CINV study group of Japan. Expert Opin Pharmacother. 2017;18(8):753-8. https://doi.org/10.1 080/14656566.2017.1317746.

26. Matsui R, Suzuki K, Takiguchi T, Nishio M, Koike T, Hayashi T, et al. 5Hydroxytryptamine-3 receptor antagonist and dexamethasone as prophylaxis for chemotherapy-induced nausea and vomiting during moderately emetic chemotherapy for solid tumors: A multicenter, prospective, observational study. BMC Pharmacol Toxicol. 2020;21:72. https://doi.org/10.1186/s40360-020-00445-y.

27. Nishimura J, Satoh T, Fukunaga M, Takemoto H, Nakata K, Ide Y, et al. Combination antiemetic therapy with aprepitant/fosaprepitant in patients with colorectal cancer receiving oxaliplatin-based chemotherapy (SENRI trial): a multicentre, randomised, controlled phase 3 trial. Eur J Cancer Oxf Engl 1990. 2015;51:1274-82.

28. ABIM. Choosing Wisely: Ten Things Physicians and Patients Should Question. https://www.asrm.org/resources/choosing-wisely-ten-thingsphysicians-and-patients-should-question/. Accessed 2 Jun 2021.

29. lihara H, Ishihara M, Fujii H, Yoshimi C, Yamada M, Suzuki A, et al. Comparison of the control of nausea and vomiting among several moderately emetic-risk chemotherapy regimens. J Cancer. 2016;7(5):569-75. https://doi.org/10.7150/jca.13637.

30. Molassiotis A, Aapro M, Herrstedt J, Gralla R, Roila F. MASCC/ESMO antiemetic guidelines: introduction to the 2016 guideline update. Support Care Cancer Off J Multinatl Assoc Support Care Cancer. 2017;25(1):267-9. https://doi.org/10.1007/s00520-016-3324-x.

31. Takemoto H, Nishimura J, Komori T, Kim HM, Ota H, Suzuki R, et al. Combination antiemetic therapy with aprepitant/fosaprepitant in patients with colorectal cancer receiving oxaliplatin-based chemotherapy in the SENRI trial: analysis of risk factors for vomiting and nausea. Int I Clin Oncol. 2017;22(1):88-95. https://doi.org/10.1007/s10147-016-1022-9.

32. Hayashi T, Shimokawa M, Matsuo K, Nishimura J, lihara H, Nakano T, et al. $5 \mathrm{HT}_{3}$ RA plus dexamethasone plus aprepitant for controlling delayed chemotherapy-induced nausea and vomiting in colorectal cancer. Cancer Sci. 2021;112(2):744-50. https://doi.org/10.1111/cas.14757.

33. Wang D-S, Hu M-T, Wang Z-Q, Ren C, Qiu M-Z, Luo H-Y, et al. Effect of Aprepitant for the prevention of chemotherapy-induced nausea and vomiting in women: a randomized clinical trial. JAMA Netw Open. 2021;4(4): e215250. https://doi.org/10.1001/jamanetworkopen.2021.5250.

\section{Publisher's Note}

Springer Nature remains neutral with regard to jurisdictional claims in published maps and institutional affiliations.

Ready to submit your research? Choose BMC and benefit from:

- fast, convenient online submission

- thorough peer review by experienced researchers in your field

- rapid publication on acceptance

- support for research data, including large and complex data types

- gold Open Access which fosters wider collaboration and increased citations

- maximum visibility for your research: over $100 \mathrm{M}$ website views per year

At $\mathrm{BMC}$, research is always in progress.

Learn more biomedcentral.com/submissions 